\title{
UNUSUAL PRESENTATION OF HEADACHE: SUPRASELLER ARACHNOID CYST
}

Prakhar Garg1, Ankit Manglunia², Piyush Kumar ${ }^{3}$, Surbhi Chaturvedi ${ }^{4}$, Ganesh Narain Saxena ${ }^{5}$

\section{HOW TO CITE THIS ARTICLE:}

Prakhar Garg, Ankit Manglunia, Piyush Kumar, Surbhi Chaturvedi, Ganesh Narain Saxena. "Unusual Presentation of Headache: Supraseller Arachnoid Cyst". Journal of Evolution of Medical and Dental Sciences 2015; Vol. 4, Issue 53, July 02; Page: 9293-9295, DOI: 10.14260/jemds/2015/1351

ABSTRACT: Headache is a common complaint in children and adolescents. Only minority percentage of headaches is associated with serious causative factors such as space occupying lesion. ${ }^{1}$ Arachnoid cysts compose less than of one percent of all intracranial lesions and they are mostly asymptomatic. Herein, we present a teenager with refractory headache diagnosed with arachnoid cyst. ${ }^{2}$

KEYWORDS: Arachnoid cyst; Headache; Intracranial lesions.

CASE REPORT: 17 year old female presented with history of headache on and off since 4 months which was diffused in nature. Headache has progressed in 15 days and has showed resistance to analgesics. Headache was associated with vomiting and vertigo. Patient also complained of fever which was associated occasionally with chills since last 10 days and milky discharge from her breasts off and on. No history of seizures, loss of consciousness, trauma or other infectious diseases. Family history of 11 deaths of her siblings, cause of death of them remains undiagnosed, 7 had complain of severe headache during their terminal phase.

Patient's vitals were normal on presentation. On neurological examination knee reflex and biceps reflex were absent bilaterally. Sensory ataxia was present. No other neurogical deficit was found. Due to refractory headache and vertigo, MRI was done which revealed suprasellar arachnoid cyst causing mild obstructive hydrocephalus with displacement of arteries in circle of Willis.

An endocrinological profile revealed the following values: normal levels of luteinizing hormone (2.92 IU/L), follicle-stimulating hormone (1.61 IU/L) and thyroid stimulating hormone (1.71 mL U/L); Prolactin levels (24.13 ng/ml) and decreased levels of cortisol (2.46 ug/dl).

DISCUSSION: Arachnoid cysts are fluid-filled sacs that occur on the arachnoid membrane that covers the brain (Intracranial) and the spinal cord (Spinal). Arachnoid cysts appear on the arachnoid membrane, and they may also expand into the space between the pia matter and arachnoid membranes (Subarachnoid space). The most common locations for intracranial arachnoid cysts are the middle fossa (near the temporal lobe), the suprasellar region (Near the third ventricle) and the posterior fossa, which contains the cerebellum, pons, and medulla oblongata. ${ }^{2}$ In most cases, arachnoid cysts are present at birth (Congenital), but usually do not cause any symptoms (Asymptomatic) throughout an individual's life. The most common symptoms associated with arachnoid cysts are usually nonspecific and include headaches, nausea, vomiting, dizziness and the accumulation of excessive cerebrospinal fluid in the brain (Hydrocephalus), resulting in increased intracranial pressure In rare cases, in some children, an arachnoid cyst can cause malformation of certain cranial bones, resulting in an abnormally enlarged head (Macrocephaly).1,2

A variety of additional symptoms occur in some individuals with arachnoid cysts depending upon the size and location of the cyst. Most cysts occur near the middle fossa region of the brain. Such symptoms include lethargy, seizures, vision abnormalities and hearing abnormalities. Neurological 
signs may be present because arachnoid cysts may cause increased pressure on structures of the brain. Such neurological findings may include developmental delays, behavioural changes, an inability to control voluntary movements (Ataxia), difficulties with balance and walking and cognitive impairment. Weakness or paralysis on one side of the body (Hemiparesis) has also been reported.

In addition to hydrocephalus, cysts located in the suprasellar region may be associated with vision disturbances, continuous bobbing of the head, and abnormalities affecting certain hormoneproducing glands that help to regulate the rate of growth, sexual development, and certain metabolic functions (Endocrine system). The exact cause of arachnoid cysts is not known. Researchers believe that most cases of arachnoid cysts are developmental malformations that arise from the unexplained splitting or tearing of the arachnoid membrane. According to the medical literature, cases of arachnoid cysts have run in families (Familial cases) suggesting that a genetic predisposition may play a role in the development of arachnoid cysts in some individuals. ${ }^{3}$

Most arachnoid cysts are found incidentally and remain constant in size, leading many physicians to recommend conservative treatment. When no symptoms are present, no treatment may be necessary and affected individuals may be periodically monitored. If symptoms arise, a cyst can be re-evaluated 4 . More recently, advancements in minimally invasive brain and skull base surgery have evolved these traditional procedures into fully endoscopic techniques, distinguished by shorter operating times, fewer complications, excellent outcomes with faster recovery and overall decreased patient morbidity. ${ }^{5}$

CONCLUSION: Spontaneous intracystic haemorrhage is an uncommon and serious complication of arachnoid cysts, which can give rise to atypical features on imaging. Therefore, familiarity with this complication and its imaging features is essential and this entity should be excluded in all cases of symptomic arachnoid cysts.

\section{REFERENCES:}

1. Helland CA, Wester K. A population based study of intracranial arachnoid cysts: clinical and neuroimaging outcomes following surgical cyst decompression in adults. J Neurol Neurosurg Psychiatry. 2007; 78: 1129-1135.

2. Bennett JC, Plum F., eds. Cecil Textbook of Medicine. 20th ed. Philadelphia, PA: W.B. Saunders Co; 1996:2131.

3. Hughes G, Ugokwe K, Benzel EC. A review of spinal arachnoid cysts. CCJM. 2008; 75: 311-315.

4. Kabil MS, Shahinian HK. Application of the supraorbital endoscopic approach to tumors of the anterior cranial base. J Craniofac Surg. 2005; 16: 1070-1074.

5. Greenfield JP, Souweidane MM. Endoscopic management of intracranial cysts. Neurosurg Focus. 2005; 19: E7. 


\section{CASE REPORT}

\section{AUTHORS:}

1. Prakhar Garg

2. Ankit Manglunia

3. Piyush Kumar

4. Surbhi Chaturvedi

5. Ganesh Narain Saxena

\section{PARTICULARS OF CONTRIBUTORS:}

1. $3^{\text {rd }}$ Year Resident, Department of Medicine, Mahatma Gandhi Medical College \& Hospital, Jaipur.

2. $2^{\text {nd }}$ Year Resident, Department of Medicine, Mahatma Gandhi Medical College \& Hospital, Jaipur.

3. $2^{\text {nd }}$ Year Resident, Department of Medicine, Mahatma Gandhi Medical College \& Hospital, Jaipur.

\section{FINANCIAL OR OTHER}

COMPETING INTERESTS: None
4. $3^{\text {rd }}$ Year Resident, Department of Medicine, Mahatma Gandhi Medical College \& Hospital, Jaipur.

5. Professor, Department of Medicine, Mahatma Gandhi Medical College \& Hospital, Jaipur.

\section{NAME ADDRESS EMAIL ID OF THE CORRESPONDING AUTHOR:}

Dr. Prakhar Garg, \# 83/29B, Neelgiri Marg, Mansarovar, Jaipur.

E-mail: ankit.manglunia@yahoo.in

Date of Submission: 08/06/2015. Date of Peer Review: 09/06/2015. Date of Acceptance: 26/06/2015. Date of Publishing: 02/07/2015. 